Article

\title{
The Effect of a Weekly Comingled Kerbside Collection Service on Household Recycling in a Gated Community in Pretoria, South Africa
}

\author{
Jacques du Toit ${ }^{1, *(\mathbb{D})}$ and Claire Wagner ${ }^{2}$ \\ 1 Department of Town and Regional Planning, University of Pretoria, Private Bag X20, \\ Hatfield 0028, South Africa \\ 2 Department of Psychology, University of Pretoria, Private Bag X20, Hatfield 0028, South Africa; \\ claire.wagner@up.ac.za \\ * Correspondence: jacques.dutoit@up.ac.za; Tel.: +27-12-420-5765
}

Received: 31 January 2018; Accepted: 28 March 2018; Published: 17 April 2018

\begin{abstract}
Gated communities is a growing phenomenon in South Africa and abroad. The enclosed and private nature of gated communities poses certain challenges to recycling. Using the Theory of Planned Behaviour, we examine the effect of a weekly comingled kerbside collection service on household recycling in a gated community. We used an ex post facto design and surveyed and compared recycling behaviour across two separate, but comparable communities; Boardwalk Meander, with no service, and Silver Lakes, with a service. Factor analyses validated the construct 'perceived behavioural control' in both settings. Households in Silver Lakes were more than three times likely to recycle in comparison to Boardwalk Meander. Multivariate Analysis of Variance suggests that the service had an overall significant effect on attitude, subjective norm and control. Post hoc tests suggest that recyclers in Silver Lakes felt equally positive, but more pressured and able to recycle, as compared to recyclers in Boardwalk Meander. Significantly more recyclers and non-recyclers in Silver Lakes felt they had enough space to recycle, as compared to their counterparts in Boardwalk Meander, even though house and yard sizes were the same across the two settings. We conclude with policy, planning and design recommendations for facilitating comingled kerbside collection in gated communities.
\end{abstract}

Keywords: comingled kerbside recycling; household recycling; gated community; theory of planned behaviour; exploratory factor analysis; multivariate analysis of variance

\section{Introduction}

South African legislation currently requires integrated waste management and is aimed at establishing separation at source in urban areas by 2016 [1,2]. Current levels of recycling in South Africa are, however, very low [3]. In 2012, only about $10 \%$ of all waste was recycled [4], while only about $3.3 \%$ of households recycled [5]. With full separation at source a distant goal in South Africa, comingled kerbside collection currently appears to be the most viable option to encourage household participation in recycling. Many households in South Africa, though, find themselves in enclosed residential developments that present challenges to kerbside collections, such as restricted access, privatised space, and management rules.

Gated communities are one type of enclosed development that has increased noticeably in South Africa. Such communities are 'residential areas with restricted access in which normally public spaces are privatized' [6]. Landman and Badenhorst [7] identify two main types of gated communities in South Africa, i.e., enclosed neighbourhoods (existing neighbourhoods that are closed off in retrospect), 
and security villages/developments (new private gated developments for residential or non-residential use). Security villages/developments have four subtypes, i.e., large luxury estates, gated townhouse complexes, gated apartments, and non-residential gated parks. Although precise data are lacking on the proportion of people or households in South Africa living in gated communities, Landman and Badenhorst [7] have shown that gated communities have recently had a considerable impact on spatial transformation in Johannesburg. In security developments and large luxury estates in particular, access is typically controlled by perimeter fencing or walls and most often $24 \mathrm{~h}$ security that regulates entrance for non-residents. Collection of recyclables by formal and/or informal recyclers would thus be restricted, if not impossible, while access is usually only granted for municipal collection of residual waste. Residents also tend to define themselves as tight-knit communities which offers the opportunity to study community effects on recycling, a factor that has been shown to increase recycling [8-10].

Previous research on socio-spatial factors affecting household recycling in townhouses (another type of enclosed development) has shown the importance of providing appropriate recycling facilities for specific housing types [11]. While it has been shown that households in Exeter (UK) and Kuala Lumpur (Malaysia) were more likely to recycle with access to kerbside collection [12-14], few studies have examined the effect of comingled kerbside collection on household recycling in specific residential settings. One study on waste management in middle-class gated communities in Bangalore (India) suggests that community-led initiatives for segregation at source are successful due to peer pressure and strong social networks [15]. Some recent comparisons of recycling schemes of different maturity have shown that the presence/absence of a convenient kerbside collection service is the most important factor behind increased household sorting [16-18]. Good communication and clear information about what to recycle are also key drivers [17,19], especially when introducing new programmes or making changes to existing ones [20]. Comingled kerbside collection results in higher participation rates than single material collection [21,22], although it may result in a lower percentage of recyclable material due to contamination [23]. To our knowledge there are no published studies in the framework of the Theory of Planned Behaviour that examine the effect of comingled kerbside collection on household recycling in the context of gated communities or security developments in particular.

Given the unique features of gated communities, especially security developments, what effect can comingled kerbside collection services have on household recycling, and how may planners respond to help facilitate recycling in security developments? We examine the effect of a comingled kerbside collection service on household recycling by comparing responses in Silver Lakes, a large luxury estate with such a service, with responses in Boardwalk Meander, a similar large luxury estate, but with no such service. We first present the Theory of Planned Behaviour followed by a discussion of the study method. We then present results in terms the (1) socio-demographic profile of respondents; (2) construct validity; and (3) effect on actual household recycling and the determinants of recycling. We conclude with policy, planning and design recommendations for facilitating comingled kerbside collection in security developments.

\section{Theoretical Framework}

We used Ajzen's [24] well-known Theory of Planned Behaviour (TPB) as a theoretical framework considering its applicability to environmental behaviour, especially recycling [25-28]. According to the TPB, there are three determinants of behaviour, including 'attitude' towards the behaviour (i.e., perceptions about the consequences of performing the behaviour), 'subjective norm' (i.e., perceptions of others' expectations to perform the behaviour, notably social pressure), and 'perceived behavioural control' (PBC) (i.e., perceptions of how much control one has to perform the behaviour, notably the ability to perform the behaviour). The interaction between these determinants leads to an intention to perform the behaviour followed by the behaviour itself. The TPB basically suggests that if people's feelings about a certain behaviour are positive, they feel expected to perform the behaviour, and they feel they are able to do so, then their intention to perform the behaviour should be strong and they would most probably perform the behaviour [29]. 
Some studies on recycling include additional determinants, such as moral norm, past experience and perceived consequences of recycling $[25,28]$. We found the original framework of the TPB sufficient to address our main question about the overall effect of a recycling service on recycling behaviour in a security development. Given our focus on a security development, we were particularly interested in the role of spatial and physical factors relative to social factors. For us the construct of PBC presented a conceptual category within which to address spatial and physical factors, though we had a wider understanding of PBC to include situational factors such as storage space and access to recycling facilities [29]. This study is arguably one of the first to examine the applicability of the TPB in examining the effect of a comingled kerbside collection service on household recycling in a gated community, specifically a security development, and can therefore provide a basis for further studies that may include additional constructs or examine the effect of comingled kerbside collection services in other types of enclosed residential developments.

\section{Method}

\subsection{Research Design and Setting}

We used an ex post facto design for this study. In order to examine the effect of a recycling service on recycling behaviour in a security development, we conducted a survey in two separate, but comparable communities, one that had a service, and one that did not. We used the same sampling technique and questionnaire and compared responses between the two communities. The design is therefore similar to a pre-experimental static group comparison, but without a control. Although ex post facto studies lack the same control of experimental designs, it is nevertheless a legitimate design and applicable to the current setting and question posed in this study [30,31]. Thus, instead of emphasising cause-and-effect, we focused on how differences in recycling behaviour between the two settings were associated with the presence/absence of a recycling service.

We conducted the surveys in Boardwalk Meander and Silver Lakes, two high-income security estates on the eastern edge of Pretoria, the administrative capital of South Africa. Although both communities are located on the eastern edge and are considered high-income relative to most other neighbourhoods in Pretoria, they are approximately $6 \mathrm{~km}$ apart and have no direct bearing or influence on each other. Consumer surveys suggest that Pretoria east had the highest average monthly household income in urban South Africa during 2016 at R28974 or approximately $\$ 2426$ as at March 2018 exchange rates. Both communities are access-controlled with a closed- or hierarchical road network and luxurious freestanding houses on individual stands. Both communities are privately managed, while the role of the local authority is limited to regulation and provision of bulk services. Average stand sizes are approximately $1060 \mathrm{~m}^{2}$ in Boardwalk Meander and $1090 \mathrm{~m}^{2}$ in Silver Lakes, with a coverage of $50 \%$ and average house size of approximately $350 \mathrm{~m}^{2}$ in both estates. Boardwalk Meander has approximately 260 stands while Silver Lakes has approximately 1200 stands. Figures 1 and 2 show the layout plans of Boardwalk Meander and Silver Lakes.

Although Boardwalk Meander is smaller than Silver Lakes in terms of number of stands, the spatial and physical comparability between them is evident, i.e., the physical and spatial features that may influence household recycling, such as accessibility, layout, stand size, housing type, road reserve, and kerbside design, are similar. At the time of the study, both estates were serviced by weekly municipal refuse collection requiring households to put out wheelie-bins on the kerbside. The municipal service required no separation or recycling and collected all forms of materials and waste except garden refuse, building rubble, and other forms of hazardous or toxic waste that would otherwise be considered illegal. Boardwalk Meander had no formal recycling service inside the estate in addition to the standard municipal service. Residents would have had to take recyclables to different collection points for different materials at nearby schools, offices, or shopping centres. Silver Lakes, on the other hand, had a free weekly comingled kerbside collection service that was already in place at the time of our study. Residents would place any paper, glass, metal or plastic 
(i.e., dry recyclables) in any of their own bags and put it out on the kerbside every morning of a specific day of the week. The estate management used their own staff and vehicles to collect the bags and to take it to a central point inside the estate where the materials were separated. The management then arranged access for different private recycling companies to collect different respective materials from the estate. The service therefore involved no costs to residents at the time of our study. We selected Silver Lakes as it was the only gated community in Pretoria east that we were aware of that had a weekly comingled collection service in place at the time of our study, and Boardwalk Meander based on its comparability with Silver Lakes and lack of recycling services.

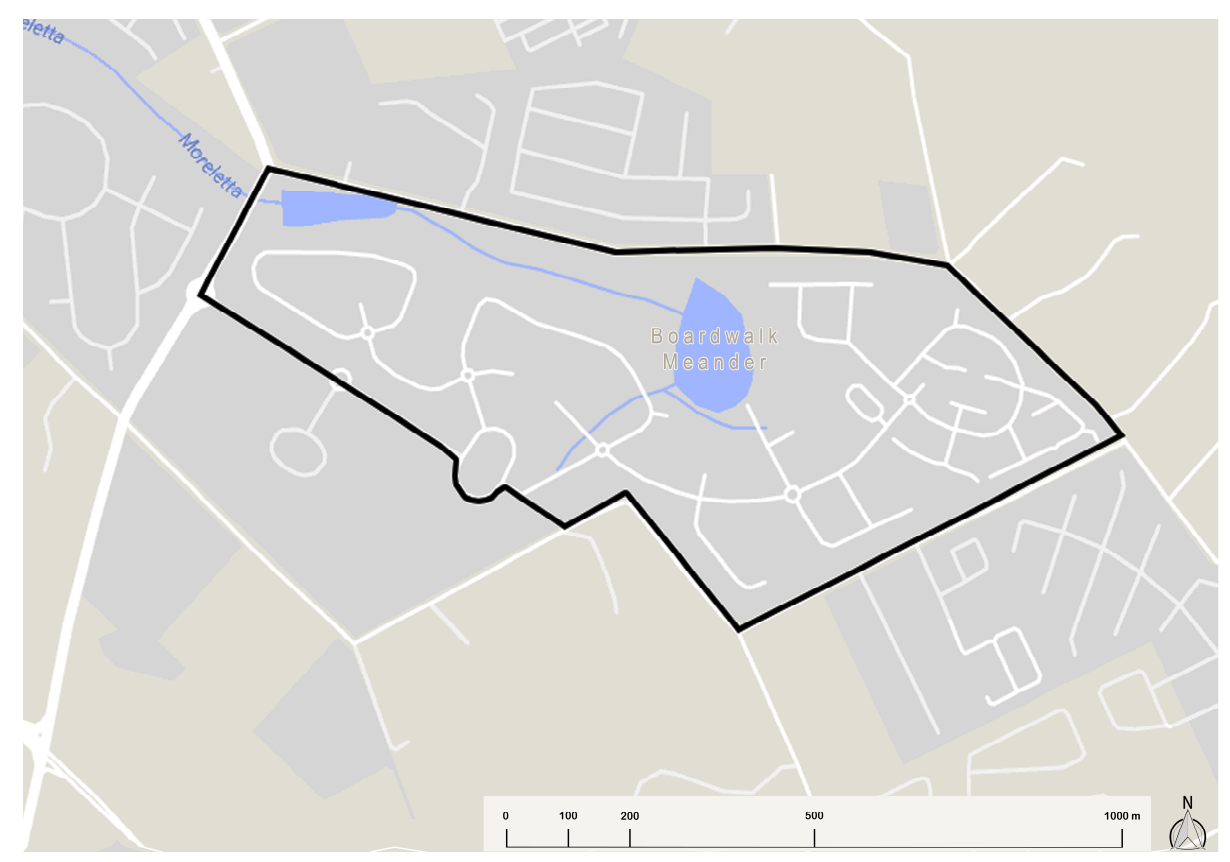

Figure 1. Layout plan of Boardwalk Meander.

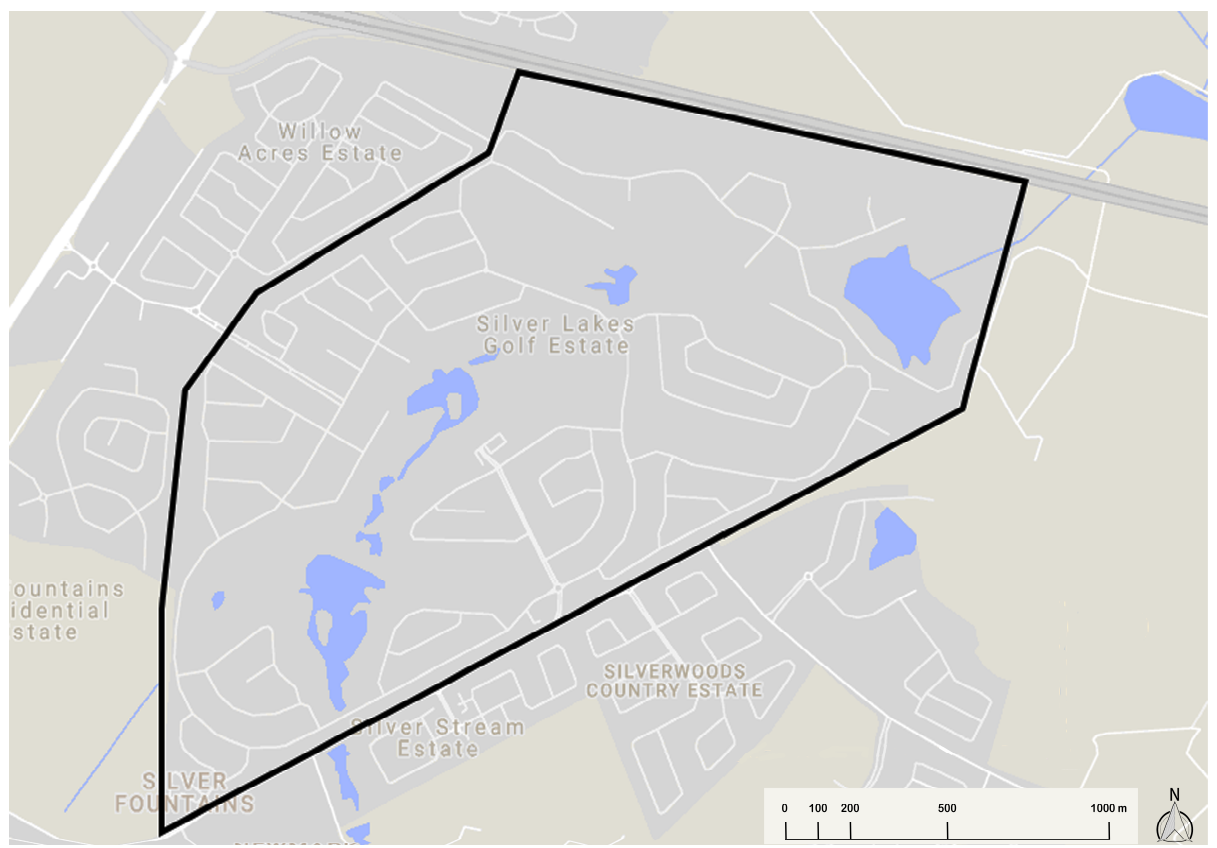

Figure 2. Layout plan of Silver Lakes. 


\subsection{Measurement and Questionnaire Design}

Using the TPB, we designed a questionnaire to capture the basic socio-demographic characteristics and recycling behaviour of households (see Annexure 1). Table 1 shows the items we formulated to measure the constructs of 'attitude' (towards recycling), 'subjective norm' (social pressure), and PBC (ability to recycle).

Table 1. Questionnaire items used to measure Theory of Planned Behaviour (TPB) constructs.

\begin{tabular}{|c|c|c|}
\hline Attitude (Towards Recycling) & Subjective Norm (Social Pressure) & Perceived Behavioural Control (Ability to Recycle) \\
\hline $\begin{array}{l}\text { "Please indicate the extent to which } \\
\text { you agree or disagree with the } \\
\text { following statements:" }\end{array}$ & $\begin{array}{l}\text { "Please indicate the extent to which you agree } \\
\text { or disagree with the following statements:" }\end{array}$ & $\begin{array}{c}\text { "On a scale of } 1 \text { to } 5 \text {, with ' } 1 \text { ' being 'not at all', and ' } 5 \text { ' } \\
\text { being 'to a large extent', to what extent ..." }\end{array}$ \\
\hline $\begin{array}{l}\text { Recycling is important for the sake of } \\
\text { the environment. (A1) } \\
\text { Recycling is not worth the cost } \\
\text { incurred by recycling companies. (A2) } \\
\text { Recycling is important to help reduce } \\
\text { waste in municipal landfills. (A3) } \\
\text { Recycling is not worth the effort } \\
\text { incurred by households. (A4) }\end{array}$ & $\begin{array}{l}\text { My family and friends would like me to } \\
\text { recycle my household waste. (SN1) } \\
\text { My neighbours would approve of me recycling } \\
\text { my household waste. (SN2) } \\
\text { My local authority (City of Tshwane) expects } \\
\text { me to recycle my household waste. (SN3) }\end{array}$ & $\begin{array}{l}\text {... do you have information on what, where, when and } \\
\text { how to recycle? (PBC1) } \\
\ldots \text { is there sufficient space or facilities within your house } \\
\text { to do recycling? (PBC2) } \\
\ldots \text { is there sufficient space or facilities in your yard to do } \\
\text { recycling? (PBC3) } \\
\ldots \text { is there sufficient space or facilities inside your estate } \\
\text { to do recycling? (PBC4) } \\
\ldots \text { does your body corporate or resident association } \\
\text { promote or support recycling inside your estate? (PBC5) } \\
\ldots \text { do recycling companies have access to your estate to } \\
\text { collect recyclables? (PBC6) } \\
\ldots \text { do you have access to a kerbside or collection point for } \\
\text { recycling just outside your estate? (PBC7) }\end{array}$ \\
\hline
\end{tabular}

We discuss the formulation of these items in more detail in a similar study about recycling in townhouses in the same special issue of Waste, Space, and Place [11]. The main points are summarised below.

Attitude and subjective norm were measured with four and three statements respectively about recycling followed by five-point Likert scales ranging from 'agree completely', 'agree to some extent', 'neither agree nor disagree', 'disagree to some extent', to 'disagree completely' (e.g., see Martin et al. [32]). PBC was measured with seven questions about the household's ability to recycle followed by five-point numbered scales ranging from 'not at all' towards 'to a large extent'. To measure PBC we followed a similar approach to Tonglet et al. [25] and Davies et al. [29] by using a combination of traditional items (ease and opportunity) and facilitating/inhibiting items (knowledge and resources).

Our conceptualisation of 'attitude' conforms to Wan et al.'s [33] conception of an experiential and instrumental dimension to attitude, though we did not include a cognitive dimension (i.e., knowledge about the consequences of recycling) as suggested by Davies et al. [29]. We also conceptualised social norms in terms of injunctive norms only, i.e., the perceived expectation by others to recycle, without any descriptive norms, i.e., the knowledge that others recycle [34]. Instead, we measured social norms by relating each item to a specific social group instead of the unspecified phrase '... most people who are important to me ... ' used in certain studies (e.g., see Tonglet et al. [25]).

Considering that the construct of 'intention' has been criticised for failing to predict actual behaviour [29], we did not measure intentions to recycle as per the original TPB framework. Instead, we captured actual recycling with a question that asked respondents whether their households had recycled any paper, glass, metal or plastic (i.e., dry recyclables) in the past three months followed by a binary 'yes/no' response.

We translated the questionnaire to include an Afrikaans version, piloted both the English and Afrikaans versions, and submitted final versions for ethical clearance. The Research Ethics Committee of the Faculty of Engineering, Built Environment, and Information Technology at the University of Pretoria granted clearance on the 19th of May 2014 (reference number EBIT/16/2014). The clearance required informed consent, voluntary participation, and anonymity of responses. 


\subsection{Data Collection}

Using base maps of Boardwalk Meander and Silver Lakes that showed individual stands, we numbered each stand and randomly sorted stand numbers using Excel (Microsoft Corporation, Redmond, WA, USA). After we negotiated access with the management of Boardwalk Meander and Silver Lakes, 18 undergraduate students in Town and Regional Planning, who participated in the study as part of their final year research project, surveyed households in both communities using the randomly sorted lists of stand numbers and self-administered questionnaires. The planning students were trained and mentored by research psychology master's students on various aspects of fieldwork, data analysis and report writing (see Wagner, Du Toit and Venter [35]).

Considering that we obtained ethical clearance to survey residents of 19 years or older (i.e., residents past the school-going age in South Africa), the students identified a member of 19 years or older in each household who was the most appropriate person to answer the questionnaire. The students introduced the study, obtained informed consent, and then asked respondents to complete the questionnaire in their presence. The students could therefore assist respondents with clarifying questions and encourage non-recycling households to participate if they thought the study applied to recyclers only.

Students were able to survey 131 households in Boardwalk Meander after which they started encountering saturation, yielding a sample of approximately $50 \%$. In Silver Lakes they were able to survey 300 households within the time they were granted access, yielding a sample of approximately $25 \%$. Upon completion of the survey, random spot-checks were conducted on a small sample of completed questionnaires collected by each student. After authenticating each student's batch of questionnaires, data were captured, cleaned, and analysed.

\subsection{Data Analysis}

We analysed the data using SPSS 24 (International Business Machines Corp., Armonk, NY, USA). Since some of the Likert scales were reversed, we were able to identify a response set in nine cases, one in Boardwalk Meander and eight in Silver Lakes. These cases were removed to yield a final sample of 422 valid responses $(n=422) ; 130$ from Boardwalk Meander $(n=130)$ and 292 from Silver Lakes $(n=292)$. We first conducted an exploratory factor analysis for Boardwalk Meander and Silver Lakes to determine the construct validity of the 14 individual TPB items in each setting. We then conducted a chi-square test to determine the effect of the recycling service on household participation, followed by a Multivariate Analysis of Variance (MANOVA) and post hoc tests to determine the overall effect of the service on the determinants of recycling behaviour (attitude, subjective norm and PBC). We followed up the MANOVA with chi-square tests for group differences and a measure of association across each of the 14 TPB items. Statistical significance was calculated at the 0.05 level.

\section{Results and Discussion}

\subsection{Socio-Demographic Profile of Respondents}

Table 2 shows the socio-demographic profile of respondents at Boardwalk Meander and Silver Lakes in terms of gender, age, highest level of education completed, and position in the household. 
Table 2. Socio-demographic profile of respondents at Boardwalk Meander and Silver Lakes.

\begin{tabular}{|c|c|c|c|c|c|}
\hline & \multirow{2}{*}{ Socio-Demographics } & \multicolumn{2}{|c|}{ Boardwalk Meander } & \multicolumn{2}{|c|}{ Silver Lakes } \\
\hline & & $n$ & $\%$ & $n$ & $\%$ \\
\hline \multirow{3}{*}{ Gender } & Female & 82 & 63.1 & 191 & 65.4 \\
\hline & Male & 48 & 36.9 & 101 & 34.6 \\
\hline & Total & 130 & 100.0 & 292 & 100.0 \\
\hline \multirow{4}{*}{ Age } & 19-35 Years & 33 & 25.4 & 49 & 16.8 \\
\hline & 36-59 Years & 87 & 66.9 & 193 & 66.1 \\
\hline & $60+$ Years & 10 & 7.7 & 50 & 17.1 \\
\hline & Total & 130 & 100.0 & 292 & 100.0 \\
\hline \multirow{5}{*}{$\begin{array}{l}\text { Highest level of } \\
\text { education } \\
\text { completed }\end{array}$} & Matric/Grade 12 or less & 22 & 16.9 & 55 & 19.1 \\
\hline & Certificate or diploma & 31 & 23.8 & 73 & 25.3 \\
\hline & Bachelor or honours & 57 & 43.8 & 105 & 36.5 \\
\hline & Masters or doctoral & 20 & 15.4 & 55 & 19.1 \\
\hline & Total & 130 & 100.0 & $288^{1}$ & 100.0 \\
\hline \multirow{4}{*}{$\begin{array}{c}\text { Position in the } \\
\text { household }\end{array}$} & Head of the household & 52 & 40.0 & 110 & 38.3 \\
\hline & Spouse of the head of the household & 64 & 49.2 & 149 & 51.9 \\
\hline & $\begin{array}{l}\text { Other (e.g., dependent) or not } \\
\text { applicable (e.g., cohabiting) }\end{array}$ & 14 & 10.8 & 28 & 9.8 \\
\hline & Total & 130 & 100.0 & $287^{2}$ & 100.0 \\
\hline
\end{tabular}

${ }^{1}$ Four respondents did not indicate their level of education; ${ }^{2}$ Five respondents did not indicate their position in the household.

At the time of the study, household members in Boardwalk Meander and Silver Lakes who were mainly responsible for recycling were, in both settings, predominantly female, 36 to 59 years old, qualified at a tertiary level, and described themselves as the spouse of the head of the household. The average household size was approximately 3.6 persons in Boardwalk Meander and 3.8 persons in Silver Lakes, while the average number of children per household was approximately 1.4 in Boardwalk Meander and 1.3 in Silver Lakes. Chi-square tests revealed no statistically significant differences in the socio-demographics between the two settings, except with regard to age $\chi^{2}(2)=9.063, p=0.01$. Yet, Table 2 shows that the bulk of respondents in both settings ( $67 \%$ and $66 \%$ respectively) fell in the same age category of 36 to 59 years old. Boardwalk Meander had a larger proportion of younger respondents while Silver Lakes had a larger proportion of older respondents. The two settings are therefore comparable with regard to socio-demographics. Although this does not mean that we controlled for the possible influence of socio-demographics during the surveys, it does suggest that responses can be compared between the two settings with reasonable confidence.

\subsection{Construct Validity}

We conducted two separate exploratory factor analyses for Boardwalk Meander and Silver Lakes to determine the construct validity of the 14 TPB items. Both analyses were conducted using principal component analysis (PCA) with an Oblimin rotation and Kaizer normalisation. For Boardwalk Meander, the Kaiser-Meyer-Olkin measure verified the sampling adequacy for the analysis, $\mathrm{KMO}=0.65$, suggesting a weak though acceptable sample according to Field [36]. All $14 \mathrm{KMO}$ values, except two (A3 and SN3), were above the acceptable limit of 0.5 [36]. Respondents' uncertainties or differing views about the impact on landfills and the expectations of the local authority might have played a role here. However, Barlett's test of sphericity $\chi^{2}(91)=344.491, p<0.001$, indicated that correlations between items were sufficiently large for PCA. Three factors were specified to correspond with the TPB. All three factors had initial eigenvalues over Kaiser's criterion of 1 and in combination explained $45.4 \%$ of the variance. Table 3 shows the factor loadings for Boardwalk Meander after rotation. 
Table 3. Summary of the PCA results for the TPB constructs at Boardwalk Meander. $(n=118)$.

\begin{tabular}{|c|c|c|c|}
\hline \multirow{2}{*}{ Item } & \multicolumn{3}{|c|}{ Rotated Factor Loadings (Pattern Matrix) } \\
\hline & 1 & 2 & 3 \\
\hline $\begin{array}{l}\text {.. does your body corporate or resident association promote or support } \\
\text { recycling inside your estate? (PBC5) }\end{array}$ & 0.761 & & \\
\hline $\begin{array}{l}\text {.. do recycling companies have access to your estate to collect } \\
\text { recyclables? (PBC6) }\end{array}$ & 0.704 & & \\
\hline ... do you have information on what, where, when and how to recycle? (PBC1) & 0.676 & & \\
\hline $\begin{array}{l}\ldots \text { is there sufficient space or facilities inside your estate to do } \\
\text { recycling? (PBC4) }\end{array}$ & 0.631 & & \\
\hline $\begin{array}{l}\text {... do you have access to a kerbside or collection point for recycling just outside } \\
\text { your estate? (PBC7) }\end{array}$ & 0.493 & & \\
\hline Recycling is worth the effort incurred by households. (A4) ${ }^{1}$ & & 0.742 & \\
\hline My neighbours would approve of me recycling my household waste. (SN2) & & 0.673 & \\
\hline$\ldots$ is there sufficient space or facilities in your yard to do recycling? (PBC3) & $(0.419)$ & -0.597 & \\
\hline Recycling is worth the cost incurred by recycling companies. (A2) ${ }^{1}$ & & 0.547 & \\
\hline $\begin{array}{l}\ldots \text { is there sufficient space or facilities within your house to do } \\
\text { recycling? (PBC2) }\end{array}$ & $(0.468)$ & -0.539 & \\
\hline Recycling is important for the sake of the environment. (A1) & & & 0.616 \\
\hline My family and friends would like me to recycle my household waste. (SN1) & & $(0.402)$ & 0.501 \\
\hline Recycling is important to help reduce waste in municipal landfills. (A3) & & & 0.478 \\
\hline $\begin{array}{l}\text { My local authority (City of Tshwane) expects me to recycle my household } \\
\text { waste. (SN3) }\end{array}$ & & & 0.368 \\
\hline Initial eigenvalues & 3.17 & 1.91 & 1.28 \\
\hline$\%$ of variance & 22.6 & 13.7 & 9.1 \\
\hline
\end{tabular}

${ }^{1}$ The original questionnaire items that were phrased in the negative were reversed for the factor analysis.

The items that cluster on the same components suggest that component 1 represents perceived behavioural control, component 2 represents all three constructs, and component 3 represents attitude and subjective norm. However, the two control factors under component 2 load equally well onto component 1, validating the construct of control in Boardwalk Meander, whereas attitude and subjective norm do not appear to be distinct constructs.

For Silver Lakes, the Kaiser-Meyer-Olkin measure provided a stronger verification of the sampling adequacy compared to Boardwalk Meander, $\mathrm{KMO}=0.75$, suggesting a good sample according to Field [36]. All $14 \mathrm{KMO}$ values were $>0.6$, which is well above the acceptable limit of 0.5. Moreover, Barlett's test of sphericity $\chi^{2}(91)=987.38, p<0.001$, indicated that correlations between items were sufficiently large for PCA. Again, three factors were specified to correspond with the TPB. All three factors had initial eigenvalues over Kaiser's criterion of 1 and in combination explained $51.8 \%$ of the variance. Table 4 shows the factor loadings for Silver Lakes after rotation. 
Table 4. Summary of the PCA results for the TPB constructs at Silver Lakes. $(n=235)$.

\begin{tabular}{|c|c|c|c|}
\hline \multirow{2}{*}{ Item } & \multicolumn{3}{|c|}{ Rotated Factor Loadings (Pattern Matrix) } \\
\hline & 1 & 2 & 3 \\
\hline $\begin{array}{l}\text {.. does your body corporate or resident association promote or support } \\
\text { recycling inside your estate? (PBC5) }\end{array}$ & 0.908 & & \\
\hline $\begin{array}{l}\text {... do recycling companies have access to your estate to collect } \\
\text { recyclables? (PBC6) }\end{array}$ & 0.871 & & \\
\hline $\begin{array}{l}\text {... do you have information on what, where, when and how to } \\
\text { recycle? (PBC1) }\end{array}$ & 0.723 & & \\
\hline $\begin{array}{l}\text {... do you have access to a kerbside or collection point for recycling just } \\
\text { outside your estate? (PBC7) }\end{array}$ & 0.456 & & \\
\hline My family and friends would like me to recycle my household waste. (SN1) & & 0.730 & \\
\hline Recycling is important to help reduce waste in municipal landfills. (A3) & & 0.698 & \\
\hline My neighbours would approve of me recycling my household waste. (SN2) & & 0.688 & \\
\hline Recycling is important for the sake of the environment. (A1) & & 0.670 & \\
\hline Recycling is worth the cost incurred by recycling companies. (A2) ${ }^{1}$ & & 0.461 & \\
\hline Recycling is worth the effort incurred by households. (A4) ${ }^{1}$ & & 0.416 & $(-0.400)$ \\
\hline $\begin{array}{l}\text { My local authority (City of Tshwane) expects me to recycle my household } \\
\text { waste. (SN3) }\end{array}$ & & 0.411 & \\
\hline$\ldots$ is there sufficient space or facilities in your yard to do recycling? (PBC3) & & & 0.874 \\
\hline $\begin{array}{l}\ldots \text { is there sufficient space or facilities within your house to do } \\
\text { recycling? (PBC2) }\end{array}$ & & & 0.835 \\
\hline $\begin{array}{l}\ldots \text { is there sufficient space or facilities inside your estate to do } \\
\text { recycling? (PBC4) }\end{array}$ & & & 0.540 \\
\hline Initial eigenvalues & 3.86 & 2.17 & 1.23 \\
\hline$\%$ of variance & 27.5 & 15.5 & 8.8 \\
\hline
\end{tabular}

As with Boardwalk Meander, the items that cluster on the same components suggest that component 1 represents perceived behavioural control, whereas component 2 represents attitude and subjective norm. The three remaining control factors that loaded separately onto component 3 are about the availability of space for recycling, suggesting 'space' to be a distinct construct. Again, attitude and subjective norm do not appear to be distinct from each other.

We repeated both PCAs specifying two factors only. For Boardwalk Meander, five of the seven control items loaded onto component 1 , while the remaining two also loaded reasonably well onto component 1 (0.325 and 0.388). All the attitudinal and normative items loaded separately onto component 2. For Silver Lakes, all the control factors, including those around 'space', loaded onto component 1 , while all the attitudinal and normative items loaded separately onto component 2.

The construct validity in this study differs to the validity we obtained in our study in townhouses, in which a confirmatory factor analysis on the same questionnaire verified the three-factor model of the ТРВ [11]. Respondents in the exclusively higher income communities of Boardwalk Meander and Silver Lakes are arguably more homogeneous in terms of socio-demographic profile and economic status compared to respondents in the middle income townhouse estates, suggesting that respondents in Boardwalk Meander and Silver Lakes perhaps do not really differentiate between their own attitudes towards recycling and the perceived expectations of their neighbours (hence, their neighbours' own attitudes towards recycling). Still, the exploratory factor analyses in this study clearly validated 'control' as a distinct construct, with 'control' being one of the more important determinants in terms of examining the effect of recycling services in gated communities. Moreover, the conflation of attitude and subjective norm does not necessarily change the main outcome of the study. 


\subsection{Effect on Actual Household Recycling and the Determinants of Recycling}

With regard to the effect on actual household recycling, a chi-square test and Phi-coefficient revealed a highly significant but moderate association between the weekly comingled kerbside collection service and actual household recycling $\chi^{2}(1)=32.169, p<0.000, \varphi=-0.277$, with $82.4 \%$ of households in Silver Lakes having recycled paper, glass, plastic or metal (i.e., dry recyclables) in the past three months at the time of the survey, compared to only $56.2 \%$ of households in Boardwalk Meander. The odds of households recycling were 3.65 times higher in Silver Lakes with the service compared to Boardwalk Meander without the service. However, considering social desirability bias and the tendency for self-reported recycling to be overstated, the actual rate of recycling in both settings is likely to be lower [34,37-40]. Operations staff at Silver Lakes confirmed that apart from our survey, there have not been any other attempts to determine recycling participation. Further research may focus on monitoring set out rates to determine and compare actual participation with reported participation.

We conducted a MANOVA to examine the possible overall effect of the recycling service on the determinants of recycling (i.e., attitude, subjective norm, and PBC). We computed a single composite mean for attitude, subjective norm and PBC, and compared the three composite means across four groups, i.e., a recycling and non-recycling group in both Boardwalk Meander and Silver Lakes (i.e., $3 \times 4=12$ comparisons). Thus, we were also interested to see how the effect of the recycling service on behaviour differed between recyclers and non-recyclers in Silver Lakes, and how recyclers and non-recyclers in Silver Lakes would compare to their counterparts in Boardwalk Meander.

The assumptions of MANOVA include (1) independence, (2) random sampling, (3) multivariate normality, and (4) homogeneity of covariance matrices [36]. Our research design enabled us to meet the first two assumptions considering that households in both Boardwalk Meander and Silver Lakes were sampled randomly and interviewed independently.

The third assumption requires that each dependent variable is normally distributed within each group (requiring 12 normal distributions). We conducted a Kolmogorov-Smirnov (K-S) test on each of the distributions to compare sample scores with a normally distributed set of scores with the same mean and standard deviation. Only three of the 12 distributions were normal, while 9 were significantly non-normal $D(73)=0.229, p<0.001 ; D(56)=0.169, p<0.001 ; D(236)=0.253, p<0.001 ; D(51)=0.146$, $p<0.05 ; D(73)=0.100, p=0.07 ; D(56)=0.160, p<0.05 ; D(236)=0.141, p<0.001 ; D(51)=0.151, p<0.05$; $D(73)=0.103, p=0.05 ; D(56)=0.068, p=0.20 ; D(236)=0.158, p<0.001 ; D(51)=0.130, p<0.05$. However, Field [36] points out that the K-S test is sensitive to sample size and may yield significant results from even small deviations from normality. Moreover, P-P plots reveal some tendency towards normality in most of the distributions.

The fourth assumption requires that the variances in each group are roughly equal for each dependent variable and that the correlation between any two dependent variables is the same in all groups. For this assumption the univariate tests of equality of variances between groups should be met. We tested this assumption using Levene's test and compared the variance-covariance matrices between groups using Box's test considering the difference in sample sizes. For subjective norm and $\mathrm{PBC}$, variances were equal for the four groups $F(3,412)=0.332$, ns; $F(3,412)=0.366$, ns, but for attitude the variances were significantly different $F(3,412)=7.692, p<0.001$. Box's test was significant $F(18,141839)=2.283, p=0.001$, suggesting that the covariance matrices were significantly different between the groups and that the homogeneity assumption is violated. However, Field [36] points out that results from a MANOVA should not be trusted only when $p<0.001$ for Box's test.

While we were able to meet the first two of the four assumptions, we acknowledge that we were only able to meet the third and fourth assumptions partially. Results from the MANOVA should therefore be treated cautiously and only be used to obtain a general idea of the overall effect of the recycling service.

Using Pillai's trace, the MANOVA suggests that the recycling service had an overall significant effect on the determinants of recycling $V=0.31, F(9,1236)=15.9, p<0.001$. Therefore, not only were households in Silver Lakes that benefited from the service more than three times likely to recycle 
compared to households in Boardwalk Meander, recyclers and non-recyclers in Silver Lakes probably also felt more positive about recycling, more pressured to recycle, or more able to recycle compared to their counterparts in Boardwalk Meander. Because we do not test any specific hypothesis, we also conducted post hoc tests to compare each group to all other groups in terms of attitude, subjective norm and PBC. Table 5 shows the probability values of the post hoc tests. For attitude we used the Games-Howell procedure as Levene's test showed that variances differed between the four groups with regard to attitude. For norms and control we used Hochberg's GT2 as sample sizes differ between the four groups [36]. Table 6 shows the descriptive statistics of the MANOVA.

Table 5. Probability ( $p$ ) values of the post hoc tests.

\begin{tabular}{|c|c|c|c|c|c|}
\hline & & & \multirow{2}{*}{$\begin{array}{c}\text { Boardwalk Meander } \\
\text { Non-Recycling }\end{array}$} & \multicolumn{2}{|c|}{ Silver Lakes } \\
\hline & & & & Recycling & Non-Recycling \\
\hline \multirow{3}{*}{$\begin{array}{c}\text { Attitude } \\
\text { (Games-Howell) }\end{array}$} & Boardwalk & Recycling & 0.446 & 0.796 & $0.027^{1}$ \\
\hline & Meander & Non-recycling & & 0.059 & 0.386 \\
\hline & Silver Lakes & Recycling & & & $0.002^{1}$ \\
\hline \multirow{3}{*}{$\begin{array}{l}\text { Subjective norm } \\
\text { (Hochberg's GT2) }\end{array}$} & Boardwalk & Recycling & 0.996 & $0.003^{1}$ & 1.000 \\
\hline & Meander & Non-recycling & & $0.001^{1}$ & 0.990 \\
\hline & Silver Lakes & Recycling & & & $0.027^{1}$ \\
\hline \multirow{3}{*}{$\begin{array}{l}\text { Perceived Behavioural Control } \\
\text { (Hochberg's GT2) }\end{array}$} & Boardwalk & Recycling & $0.000^{1}$ & $0.000^{1}$ & 0.439 \\
\hline & Meander & Non-recycling & & $0.000^{1}$ & $0.000^{1}$ \\
\hline & Silver Lakes & Recycling & & & $0.002^{1}$ \\
\hline
\end{tabular}

Table 6. Descriptive statistics of the MANOVA.

\begin{tabular}{cccccc}
\hline \multirow{2}{*}{ Construct } & \multirow{2}{*}{ Statistic } & \multicolumn{2}{c}{ Boardwalk Meander } & \multicolumn{2}{c}{ Silver Lakes } \\
\cline { 3 - 6 } & & Recycling & Non-Recycling & Recycling & Non-Recycling \\
\hline \multirow{3}{*}{ Attitude } & $n$ & 73 & 56 & 236 & 51 \\
& Composite mean & 1.494 & 1.653 & 1.426 & 1.882 \\
& Standard deviation & 0.575 & 0.618 & 0.507 & 0.839 \\
\hline \multirow{3}{*}{ Subjective norm } & $n$ & 73 & 65 & 236 & 51 \\
& Composite mean & 2.368 & 2.449 & 1.953 & 2.343 \\
& Standard deviation & 0.831 & 0.866 & 0.885 & 0.971 \\
\hline \multirow{3}{*}{ Perceived Behavioural Control } & $n$ & 73 & 56 & 236 & 51 \\
& Composite mean & 3.500 & 2.892 & 4.203 & 3.750 \\
& Standard deviation & 0.842 & 0.807 & 0.795 & 0.858 \\
\hline
\end{tabular}

Of particular interest is how the recycling and non-recycling groups in Silver Lakes differ from their respective counterparts in Boardwalk Meander. Table 5 shows that the recycling group in Silver Lakes differed significantly from the recycling group in Boardwalk Meander with regard to subjective norm and PBC, but not attitude $(p<0.05, p<0.001, p=0.80)$. Table 6 shows that recyclers in Silver Lakes felt significantly more pressured as well as able to recycle compared to recyclers in Boardwalk Meander. The mere presence of a weekly comingled collection service can therefore make recyclers feel more pressured and able to recycle, supporting the view that the normative and visible nature of recycling can influence others to recycle [34,37], while the absence of such a service does not necessarily mean that recyclers who have to use other and probably less convenient means of recycling might be less positive about recycling.

Table 5 shows that non-recyclers in Silver Lakes differed significantly from non-recyclers in Boardwalk Meander with regard to PBC, but not attitude or subjective norm $(p<0.001, p=0.39$, $p=0.10$ ). Table 6 shows that non-recyclers in Silver Lakes felt significantly more able to recycle compared to non-recyclers in Boardwalk Meander. Therefore, although the presence of a recycling service can make non-recyclers feel more able to recycle, they do not necessarily feel more positive or pressured to recycle compared to non-recyclers elsewhere. This suggests that recycling services in gated communities with relatively homogeneous resident profiles may need to be coupled with 
more careful design, awareness or incentivising measures to influence the attitudes and perceptions of non-recyclers along ways other than peer pressure.

In fact, Table 6 shows that, despite the presence of a service, non-recyclers in Silver Lakes are actually less positive about recycling compared to non-recyclers in Boardwalk Meander, although this difference is not statistically significant. Standard deviations for non-recyclers in Silver Lakes are the highest across all three constructs, suggesting two opposing groups of respondents amongst non-recyclers in Silver Lakes more so than in any of the other three groups. Cross tabulations of individual TPB items confirm that, of all four groups, the largest proportion of respondents that showed negative attitudes on each of the four attitudinal items were all non-recyclers in Silver Lakes. It is therefore possible that the presence of a recycling service may actually contribute towards negative attitudes about recycling, especially if the service is perceived as, for example, a security risk or aesthetic problem. Operational staff at Silver Lakes pointed out that non-recyclers in Silver Lakes might have been put off by the sight of a mix of different types of recycling bags on sidewalks with higher levels of wind-blown litter on recycling collection days. If so, this suggests the importance of formalising kerbside collection in gated communities by providing appropriate bags and bins of the same standard as municipal services.

In addition to the MANOVA and post hoc tests, we conducted chi-square tests and calculated measures of association for the 14 individual TPB items across recycling and non-recycling groups in Boardwalk Meander and Silver Lakes. For the chi-square tests responses on the original five-point scales were recoded into three conceptually similar categories to reduce the number of cells with expected frequencies below 5. For the measures of association, we used Cramer's $V$ as variables were categorical with more than two categories. Table 7 shows the results of the chi-square tests and measures of association.

Table 7. Chi-square tests and measures of association for individual TPB items across recycling and non-recycling groups in Boardwalk Meander and Silver Lakes.

\begin{tabular}{cccccc}
\hline Construct & Item & $n$ & $\chi^{2}$ & Cramer's $\boldsymbol{~}$ & $\boldsymbol{p}$-Value \\
\hline \multirow{3}{*}{ Attitude } & A1 & 419 & $16.283^{1}$ & 0.139 & $0.012^{2}$ \\
& A2 & 407 & 10.761 & 0.115 & 0.096 \\
& A3 & 418 & $3.049^{1}$ & 0.060 & 0.803 \\
& A4 & 417 & 34.714 & 0.204 & $0.000^{2}$ \\
\hline \multirow{3}{*}{ Subjective norm } & SN1 & 415 & 30.321 & 0.191 & $0.000^{2}$ \\
& SN2 & 403 & $4.567^{1}$ & 0.075 & $0.600^{2}$ \\
& SN3 & 402 & 37.565 & 0.216 & $0.000^{2}$ \\
\hline \multirow{3}{*}{ Perceived Behavioural Control } & PBC1 & 417 & 102.916 & 0.351 & $0.000^{2}$ \\
& PBC2 & 418 & 40.337 & 0.220 & $0.000^{2}$ \\
& PBC3 & 417 & 32.620 & 0.198 & $0.000^{2}$ \\
& PBC4 & 406 & 12.916 & 0.126 & $0.044^{2}$ \\
& PBC5 & 411 & 95.525 & 0.341 & $0.000^{2}$ \\
& PBC6 & 406 & 79.891 & 0.314 & $0.000^{2}$ \\
& PBC7 & 390 & 42.188 & 0.233 & $0.000^{2}$ \\
\hline
\end{tabular}

${ }^{1}$ More than $20 \%$ of cells had expected frequencies below $5 ;{ }^{2}$ Significant at the 0.05 level.

Table 7 shows that the four groups differed significantly across all except three of the 14 items, supporting the result of the MANOVA that the recycling service had an overall significant effect on the behavioural determinants of recycling in Silver Lakes. Differences were also highly significant for most of the items $(p<0.001)$. All seven PBC items were significant, with a moderate to strong association between group and three PBC items, including PBC1 ('Do you have information on what, where, when and how to recycle?'), PBC5 ('Does your body corporate promote or support recycling inside your estate?') and PBC6 ('Do recycling companies have access to your estate to collect recyclables?'). 
Annexure 2 contains tables showing the descriptive statistics of the chi-square tests for each of the 14 individual TPB items across recycling and non-recycling groups in Boardwalk Meander and Silver Lakes. Significantly larger percentages of recyclers and non-recyclers in Silver Lakes ( $81 \%$ and $41 \%$ respectively) indicated that they had sufficient information compared to recyclers and non-recyclers in Boardwalk Meander (62\% and 19\% respectively). However, a noticeable percentage of non-recyclers in Silver Lakes (39\%) indicated that they had no information, despite the visibility of weekly kerbside collections inside the estate. This may be a deliberate response by non-recyclers to legitimise their lack of participation, or, may indicate that additional information is in fact necessary to ensure fuller participation in Silver Lakes. As expected, significantly larger percentages of recyclers and non-recyclers in Silver Lakes $(90 \%$ and $70 \%$ respectively) indicated that their body corporate fully supported recycling compared to recyclers and non-recyclers in Boardwalk Meander $(60 \%$ and $34 \%$ respectively). The weekly service in Silver Lakes therefore also raised residents' awareness of the role of the body corporate in facilitating recycling inside the estate. Similarly, significantly larger percentages of recyclers and non-recyclers in Silver Lakes (93\% and $82 \%$ respectively) confirmed that recycling companies had proper access to their estate compared to their counterparts in Boardwalk Meander ( $67 \%$ and $43 \%$ respectively).

While we indicated earlier that Boardwalk Meander and Silver Lakes are comparable with regard to average stand and house sizes, all three control items around the sufficiency of space for recycling (PBC2-4), though not strongly associated with group, yielded significant differences between groups. Interestingly, significantly larger percentages of both recyclers and non-recyclers in Silver Lakes indicated that they had sufficient space or facilities within their (1) house, (2) yard and (3) estate to recycle ((1) $70 \%$ and $47 \%$; (2) $77 \%$ and $61 \%$; (3) $75 \%$ and $70 \%$ respectively) compared to recyclers and non-recyclers in Boardwalk Meander ((1) $48 \%$ and $32 \%$; (2) $55 \%$ and $42 \%$; (3) $67 \%$ and $55 \%$ respectively). Moreover, there are no specific planning or designs features in and around houses, yards, or within the estate of Silver Lakes to facilitate recycling in such a way that it would necessarily be easier to recycle in Silver Lakes compared to Boardwalk Meander. This suggests that the weekly service in Silver Lakes probably contributed directly and indirectly to an increased sense of sufficient space, and hence ability, to recycle, even though yards and houses are not larger than in Boardwalk Meander. Directly, in the sense that recyclers, who actually participated in the service experienced just how possible it is to recycle, and that space should not have to be an issue. Indirectly, in the sense that the visibility of kerbside recycling in Silver Lakes contributed to a realisation amongst many non-recyclers that, if recycling is possible for their neighbours, it should probably be possible for them as well.

\section{Conclusions}

We examined the effect of a weekly comingled kerbside collection service on household recycling in a gated community in Pretoria, South Africa. We used an ex post facto design and surveyed and compared recycling behaviour across two separate but comparable security developments; Boardwalk Meander, with no service, and Silver Lakes, with a service. Households in Silver Lakes were more than three times likely to recycle compared to Boardwalk Meander. The service also had an overall significant effect on attitude, subjective norm and perceived behavioural control. Recyclers in Silver Lakes felt equally positive but more pressured and able to recycle compared to recyclers in Boardwalk Meander. Non-recyclers in Silver Lakes felt equally positive and pressured but more able to recycle compared to non-recyclers in Boardwalk Meander. The service, however, appeared to have a negative effect on some non-recyclers in Silver Lakes. Significantly more recyclers and non-recyclers in Silver Lakes felt they had sufficient space to recycle compared to their counterparts in Boardwalk Meander, even though house and yard sizes are similar across the two settings. We conclude with policy, planning and design recommendations for facilitating comingled kerbside collection in gated communities and security developments in the form of large luxury estates in particular. 
- Responses in this study suggest that comingled kerbside collection is certainly a viable option to not only increase household recycling in large luxury estates, but to also influence perceptions and to help foster a culture of recycling in general. For instance, residents' perceptions, especially around the availability of space, may only change once kerbside collection is actually operational and visible and residents have themselves either experienced or witnessed the ease of kerbside collection within their estates. Although some consultation with residents via the management agency of the estate ought to take place before a service is implemented, residents' initial perceptions about the service should not necessarily be a decisive factor whether to implement or not. Some experimentation with a service might be necessary before participation is optimal. In addition, existing literature provides ample guidance on planning, designing and incentivising comingled kerbside collection (e.g., see Kipperberg \& Larson [20]).

- Although we recommend that residents' initial perceptions should not necessarily be a decisive factor on whether to implement comingled kerbside collection or not, some planning, consultation and campaigning might be necessary to minimise possible negative effects that a service can have on non-recyclers. Yet, the cost of appeasing and motivating non-recyclers should be considered, especially if they are a minority. Appropriate bags and bins of the same standard as municipal services might help to mitigate negative perceptions.

- Security developments and large luxury estates in particular should be planned and designed more carefully to be accommodative of kerbside collection, particularly with regard to access, layout articulation and kerbside design. Many estates have a single entrance to reduce the cost of security. However, this also reduces accessibility and route optimisation for recycling companies. Providing access for companies on opposite sides of an estate can improve access and route optimisation. Similarly, many estates have a closed or hierarchical road network with numerous loops and dead-ends that also reduce route optimisation. While this type of layout is likely to remain a feature of security developments, such layouts can be made more permeable in order to optimise collection routes, e.g., by reducing loops, shortening dead-ends and increasing the number of four-way intersections. Road reserves should be sufficiently wide so that recyclables do not obstruct driveways or sidewalks. Small court yards for municipal and recycling bins can be placed at strategic points to reduce the visibility of bags and to minimise collection route stops.

This study is arguably one of the first to examine the applicability of the Theory of Planned Behaviour in examining the effect of a comingled kerbside collection service on household recycling in a gated community, and can, therefore, provide a basis for further studies that may include additional constructs or examine the effect of comingled kerbside collection services in other types of enclosed residential developments.

Supplementary Materials: The following are available online at http://www.mdpi.com/2071-1050/10/4/1207/s1.

Acknowledgments: The following students served as fieldworkers whilst they were final year students in the Bachelor of Town and Regional Planning at the University of Pretoria: George Allison, Gideon Allison, Dané Botha, Marius Buskes, Claudia Coetzer, Willie Erasmus, Nicholas Grainger, Carl Harding, Marthinus Kotze, Gamuchirai Mutezo, Melissa Peens, Lourens Toerien, Charné Stevens, Wiehann van den Berg, Megan van der Berg, Rochelle van Rooyen, Andries van Wyk, Magnus Wessels. Lizelle Fletcher from the Department of Statistics, University of Pretoria, suggested the use of MANOVA and post hoc tests. Niclesse Mariette from the Department of Town and Regional Planning, University of Pretoria, assisted with the compilation of Figures 1 and 2. Bea Fletcher from the firm The Town Planning Hub CC provided site information on Boardwalk Meander and Silver Lakes. We would like to thank the management and operational staff at Boardwalk Meander and Silver Lakes for granting our students permission and access to conduct the surveys, as well as all the residents who participated in the surveys.

Author Contributions: Jacques du Toit conceived, designed and led the study, and served as first author; Claire Wagner conducted parts of the literature review and served as co-author.

Conflicts of Interest: The authors declare no conflict of interest. 


\section{References}

1. Nahman, A.; Godfrey, L. Economic instruments for solid waste management in South Africa: Opportunities and constraints. Resour. Conserv. Recycl. 2010, 54, 521-531. [CrossRef]

2. Mbiba, B. Urban solid waste characteristics and household appetite for separation at source in Eastern and Southern Africa. Habitat Int. 2014, 43, 152-162. [CrossRef]

3. Simatele, D.M.; Dlamini, S.; Kubanza, N.S. From informality to formality: Perspectives on the challenges of integrating solid waste management into the urban development and planning policy in Johannesburg, South Africa. Habitat Int. 2017, 63, 122-130. [CrossRef]

4. Department of Environmental Affairs and Tourism (DEAT). National Waste Information Baseline Report. 2012. Available online: http:/ / sawic.environment.gov.za/documents/1880.pdf (accessed on 7 April 2017).

5. Oelofse, S. All South African Households in Large Centres to Separate Household Waste by 2016. 2012. Available online: http:/ / www.csir.co.za/enews/2012_nov/01.html (accessed on 7 April 2017).

6. Blakely, E.J.; Snyder, M.G. Fortress America. Gated Communities in the United States; Brooking Institution Press: Washington, DC, USA, 1999.

7. Landman, K.; Badenhorst, W. The impact of gated communities on spatial transformation in the greater johannesburg area. In Report Series produced by the South African Research Chair in Development Planning and Modelling; School of Architecture and Planning, University of the Witwatersrand: Johannesburg, South Africa, 2012.

8. Dai, Y.C.; Gordon, M.P.R.; Ye, J.Y.; Xu, D.Y.; Lin, Z.Y.; Robinson, N.K.L.; Woodard, R.; Harder, M.K. Why doorstepping can increase household waste recycling. Resour. Conserv. Recycl. 2015, 102, 9-19. [CrossRef]

9. Crociata, A.; Agovino, M.; Sacco, P.L. Neighborhood effects and pro-environmental behavior: The case of Italian separate waste collection. J. Clean. Product. 2016, 135, 80-89. [CrossRef]

10. Oskamp, S.; Harrington, M.J.; Edwards, T.C.; Sherwood, D.L.; Okuda, S.M.; Swanson, D.C. Factors influencing household recycling behavior. Environ. Behav. 1991, 23, 494-519. [CrossRef]

11. Du Toit, J.; Wagner, C.; Fletcher, L. Socio-spatial factors affecting household recycling in townhouses in Pretoria, South Africa. Sustainability 2017, 9, 2033. [CrossRef]

12. Zen, I.S.; Noor, Z.Z.; Yusuf, R.O. The profiles of household solid waste recyclers and non-recyclers in Kuala Lumpur, Malaysia. Habitat Int. 2014, 42, 83-89. [CrossRef]

13. Zen, I.S.; Siwar, C. An analysis of household acceptance of curbside recycling scheme in Kuala Lumpur, Malaysia. Habitat Int. 2015, 47, 248-255. [CrossRef]

14. Barr, S.; Ford, N.J.; Gilg, A.W. Attitudes towards recycling household waste in Exeter, Devon: Quantitative and qualitative approaches. Local. Environ. 2003, 8, 407-421. [CrossRef]

15. Ganguly, S.; Lutringer, C. Changing practices of water and waste management by the new middle classes within gated communities in Bangalore. Rev. Int. Politique Dév. 2017, 8.2, 1-15. [CrossRef]

16. Best, H.; Kneip, T. The impact of attitudes and behavioral costs on environmental behavior: A natural experiment on household waste recycling. Soc. Sci. Res. 2011, 40, 917-930. [CrossRef]

17. Miliute-Plepiene, J.; Hage, O.; Plepys, A.; Reipas, A. What motivates households recycling behaviour in recycling schemes of different maturity? Lessons from Lithuania and Sweden. Resour. Conserv. Recycl. 2016, 113, 40-52. [CrossRef]

18. Struk, M. Distance and incentives matter: The separation of recyclable municipal waste. Resour. Conserv. Recycl. 2017, 122, 155-162. [CrossRef]

19. Rousta, K.; Bolton, K.; London, M.; Dahlén, L. Quantitative assessment of distance to collection point and improved sorting information on source separation of household waste. Waste Manag. 2015, 40, $22-30$. [CrossRef] [PubMed]

20. Kipperberg, G.; Larson, D.M. Heterogeneous preferences for community recycling. Environ. Res. Econ. 2012, 53, 577-604. [CrossRef]

21. Oskamp, S.; Zelezny, L.; Schultz, P.W.; Hurin, S.; Burkhardt, R. Commingled vs. separated curbside recycling-Does sorting matter? Environ. Behav. 1996, 28, 73-91. [CrossRef]

22. Woodard, R.; Harder, M.K.; Bench, M. Participation in curbside recycling schemes and its variation with material types. Waste Manag. 2006, 26, 914-919. [CrossRef] [PubMed] 
23. Seyring, N.; Dollhofer, M.; Weißenbacher, J.; Bakas, I.; McKinnon, D. Assessment of collection schemes for packaging and other recyclable waste in European Union-28 Member States and capital cities. Waste Manag. Res. 2016, 34, 947-956. [CrossRef] [PubMed]

24. Ajzen, I. From intentions to action: A theory of planned behaviour. In Action Control: From Cognition to Behaviors; Kuhl, J., Beckman, J., Eds.; Springer: New York, NY, USA, 1985; pp. 11-39.

25. Tonglet, M.; Phillips, P.S.; Read, A.D. Using the theory of planned behaviour to investigate the determinants of recycling behaviour: A case study from Brixworth, UK. Resour. Conserv. Recycl. 2004, 41, 191-214. [CrossRef]

26. Botetzagias, I.; Dima, A.-F.; Malesios, C. Extending the Theory of Planned behavior in the context of recycling: The role of moral norms and of demographic predictors. Resour. Conserv. Recycl. 2015, 95, 58-67. [CrossRef]

27. Nduneseokwu, C.K.; Qu, Y.; Appolloni, A. Factors influencing consumers' intention to participate in a formal e-waste collection system: A case study of Onitsha, Nigeria. Sustainability 2017, 9, 881. [CrossRef]

28. Xu, L.; Ling, M.; Lu, Y.; Shen, M. Understanding household waste separation behaviour: Testing the roles of moral, past experience, and perceived policy effectiveness within the Theory of Planned behaviour. Sustainability 2017, 9, 625. [CrossRef]

29. Davies, J.; Foxall, G.R.; Pallister, J. Beyond the intention-behaviour mythology: An integrated model of recycling. Mark. Theory 2002, 2, 29-113. [CrossRef]

30. Du Toit, J.L.; Mouton, J. A typology of designs for social research in the built environment. Int. J. Soc. Res. Methodol. 2013, 16, 125-139. [CrossRef]

31. Leedy, P.D.; Ormrod, J.E. Practical Research: Planning and Design, 11th ed.; Pearson Education Limited: Essex, UK, 2015.

32. Martin, M.; Williams, I.; Clark, M. Social, cultural and structural influences on household waste recycling: A case study. Resour. Conserv. Recycl. 2006, 48, 357-395. [CrossRef]

33. Wan, C.; Shen, G.Q.; Choi, S. Experiential and instrumental attitudes: Interaction effect of attitude and subjective norm on recycling intention. J. Environ. Psychol. 2017, 50, 69-79. [CrossRef]

34. Thomas, C.; Sharp, V. Understanding the normalisation of recycling behaviour and its implications for other pro-environmental behaviours: A review of social norms and recycling. Resour. Conserv. Recycl. 2013, 79, 11-20. [CrossRef]

35. Wagner, C.; Du Toit, J.; Venter, S. Interdisciplinary near-peer mentoring: A potential future method of teaching in higher education? In Proceedings of the 3rd ISA Forum of Sociology, Vienna, Austria, 10-14 July 2016.

36. Field, A. Discovering Statistics Using SPSS, 3rd ed.; Sage Publications Limited: London, UK, 2009.

37. Lakhan, C. Out of sight, out of mind: Issues and obstacles to recycling in Ontario's multi residential buildings. Resour. Conserv. Recycl. 2016, 108, 1-9. [CrossRef]

38. Timlett, R.E.; Williams, I.D. The impact of transient populations on recycling behaviour in a densely populated urban environment. Resour. Conserv. Recycl. 2009, 53, 498-506. [CrossRef]

39. Barr, S.; Gilg, A.W.; Ford, N.J. Differences between household waste reduction, reuse and recycling behaviour: A study of reported behaviours, intentions and explanatory variables. Environ. Waste Manag. 2001, 4, 69-82.

40. Huffman, A.H.; Van der Werff, B.R.; Henning, J.B.; Watrous-Rodriguez, K. When do recycling attitudes predict recycling? An investigation of self-reported versus observed behavior. J. Environ. Psychol. 2014, 38, 262-270. [CrossRef]

(C) 2018 by the authors. Licensee MDPI, Basel, Switzerland. This article is an open access article distributed under the terms and conditions of the Creative Commons Attribution (CC BY) license (http://creativecommons.org/licenses/by/4.0/). 